\title{
CORRESPONDENCE
}

\section{PRESERVATION OF THE ANTERIOR CHAMBER}

\section{To the Editorial Committee of the British Journal OF OPHTHALmology}

SIRs,-Working on my suggestion that cannulated instruments for surgical procedures inside the anterior chamber would allow it to be reformed at will while operating (Tolia, 1958), Ernst Grieshaber of Switzerland has produced a discission needle mounted on a $1-\mathrm{ml}$. Luer lock syringe acting as a handle (Fig. 1), through which sterile normal saline can be injected into the anterior chamber (Fig. 2).

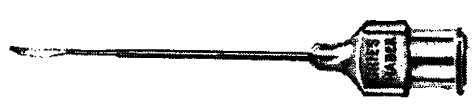

FIG. 1.

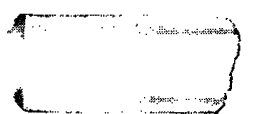

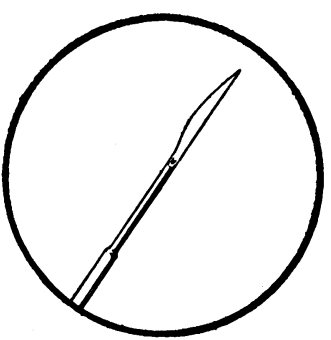

FIG. 2.

I have tried this needle in a case of traumatic cataract with an anterior synechia. I was able to do a thorough needling of the lens matter and also to divide the anterior synechia and leave the anterior chamber deep and full on the completion of the operation, thus obviating the chances of reformation of anterior synechia or iris incarceration at the site of the needle entry.

The instrument promises to be very useful in discission and capsulotomy operations. It could also easily be made to enter the potential space between the cornea and the iris from the limbus so that saline or air can be injected in cases of delayed formation of the anterior chamber after cataract and glaucoma operations.

\section{Yours faithfully,}

J. N. Tolia.

ArCade House,

P.O. BOX 10156, NAIROBI.

May 30, 1958.

\section{REFERENCE}

ToliA, J. N. (1958). Brit. J. Ophthal., 42, 60. 